\title{
Comparative analysis of load/deflection ratios of conventional and heat-activated rectangular NiTi wires
}

\author{
Fabio Schemann-Miguel', Flávio Cotrim-Ferreira², Alessandra Motta Streva ${ }^{3}$, \\ Alexander Viégas de Oliveira Aguiar Chaves ${ }^{4}$, Andréia Cotrim-Ferreira ${ }^{5}$
}

Objective: This study compared the load-deflection ratios between $0.019 \times 0.025$-in rectangular orthodontic wires using 5 conventional preformed nickel-titanium (NiTi) and 5 heat-activated NiTi archwires from four different manufacturers (Abzil, Morelli, 3M Unitek and Ormco), totaling 40 archwires. The archwires were placed in typodonts without tooth \# 11 and tested using a universal testing machine connected to a computer.

Results: The comparisons of mean load-deflection values of conventional NiTi wires revealed that the lowest meandeflection ratio was found for 3M Unitek, followed by Ormco, Morelli and Abzil. Regarding the heat-activated wires, the lowest load-deflection ratio was found for Ormco, followed by 3M Unitek, Abzil, and Morelli.

Conclusion: The comparison of mean load-deflection ratios revealed that the heat-activated wires had lowest mean load-deflection ratios, and this trend was seen during all the study. However, at 2-mm deflection, mean load-deflection ratios for heat-activated Morelli and conventional 3M Unitek wires were very similar, and this difference was not statistically significant.

Keywords: Orthodontics. Orthodontic wires. Qualitative analysis.

\footnotetext{
${ }^{1}$ Professor, Graduate Program, Specialization in Orthodontics, Santo Amaro University (UNISA), São Paulo, Brazil.

${ }^{2}$ Professor, Master's Program in Orthodontics, City of São Paulo University (UNICID), São Paulo, Brazil.

${ }^{3}$ Professor, Graduate Program, Specialization in Orthodontics, UNICID.

${ }^{4}$ Graduate Student, Master's Program in Orthodontics, UNICID.

${ }^{5}$ Professor, Lingual Orthodontics, Flavio Vellini Institute, São Paulo, Brazil.
}

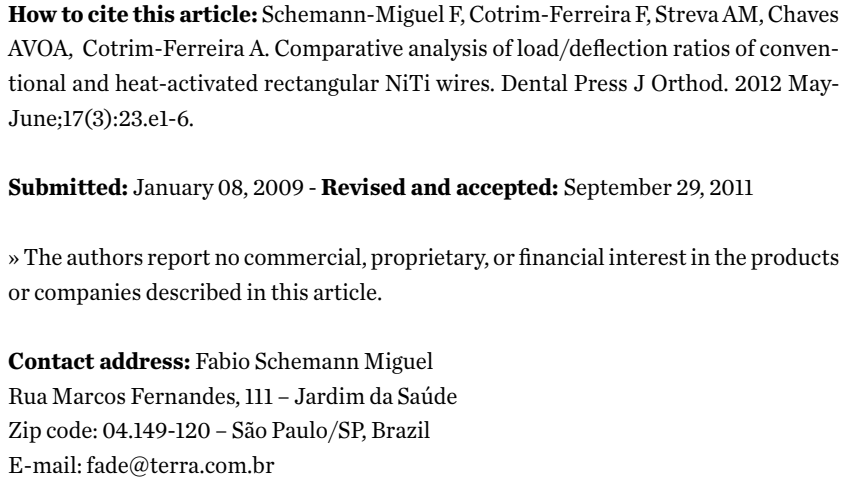

How to cite this article: Schemann-Miguel F, Cotrim-Ferreira F, Streva AM, Chaves AVOA, Cotrim-Ferreira A. Comparative analysis of load/deflection ratios of conventional and heat-activated rectangular NiTi wires. Dental Press J Orthod. 2012 MayJune;17(3):23.el-6.

Submitted: January 08, 2009 - Revised and accepted: September 29, 2011

" The authors report no commercial, proprietary, or financial interest in the products or companies described in this article.

Contact address: Fabio Schemann Miguel Rua Marcos Fernandes, 111 - Jardim da Saúde Zip code: 04.149-120 - São Paulo/SP, Brazil

E-mail:fade@terra.com.br 


\section{INTRODUCTION}

Orthodontic wires are responsible for the load that move teeth and should, therefore, be able to apply light and continuous forces. ${ }^{4}$ Several factors and characteristics should be taken into consideration when choosing orthodontic wires: thickness, cross-sectional shape, metal alloy composition, interbracket distances, type of ligatures, bracket size, friction between wire and bracket, archwire curvature ${ }^{6}$ and stress-to-strain ratio at any point, which is called modulus of elasticity. ${ }^{1}$ By definition, each orthodontic metal alloy has a modulus of elasticity that does not change, even when the wire thickness or cross section is changed. Alloys with a high modulus of elasticity are more rigid, such as stainless steel and Elgiloy, which is a chromium-cobaltnickel (Cr-Co-Ni) alloy. Those with a low modulus of elasticity are more flexible, such as titanium-molybdenum (TMA) and nickel-titanium (NiTi).

The modulus of elasticity is directly associated to the load required for the deflection of orthodontic wires, which is called the load-deflection ratio. The greater is the modulus of elasticity of a wire, higher is the load-deflection ratio and its rigidity. As the modulus of elasticity of orthodontic alloys cannot be manipulated to provide greater flexibility to the wire-appliance set, first the load-deflection ratio of the material should be known so that, later, the wire with the best indication for each phase of an orthodontic treatment can be selected.

\section{PURPOSE}

The purposes of this study, which included samples of preformed $0.019 \times 0.025$-in conventional and heat-activated NiTi wires of commercial brands available in the Brazilian market, were to:

» Evaluate the load-deflection ratio of conventional NiTi wires.

»Evaluate the load-deflection ratio of heat-activated NiTi wires.

"Compare the two types of wires.

\section{MATERIAL AND METHODS}

This study used 40 preformed orthodontic upper archwires; for each of the manufacturers listed bellow, five conventional and five heat-activated NiTi wires were selected: Morelli (Sorocaba, Bra- zil), batch number 445547 for conventional NiTi wires, and batch number 421322 for heat-activated NiTi wires; Abzil (São José do Rio Preto, Brazil), batch number 510-267 for conventional NiTi wires, and batch number 636-367 for heat-activated NiTi wires; Ormco (Orange, CA), batch number 5H09H for conventional NiTi wires, and batch number 9A259A for heat-activated NiTi wires; 3M Unitek (Saint Paul, MN), batch number REV9601 for conventional NiTi wires, and batch number B6931 for heat-activated NiTi wires;

The archwires had the same curvature and a total length of $180 \mathrm{~mm}$; they were kept at $25 \pm 2{ }^{\circ} \mathrm{C}$ ) and $50 \%$ relative humidity for 72 hours before the tests.

Wires were fixed to brackets bonded to artificial teeth of an orthodontic typodont using Morelli brackets from tooth \# 15 to tooth \# 25. Tubes were bonded to the first molars on both sides. The brackets and tubes, all manufactured by Morelli, had 0.022 x 0.030-in slots. The orthodontic wires were fixed to the brackets using clear elastic Morelli ligatures (batch number 360667). The segment of wire under test, measuring $16 \mathrm{~mm}$, was placed between the bracket on tooth \# 21 and the bracket on tooth \# 12.

The typodont was then assembled to a universal testing machine using a platform made up of two 10 -mm thick plates at a 90 degree angle with the ground.

The machine used for trials was an Emic 10000 MUE 003 manufactured in Brazil by Equipamentos de Sistemas de Ensaios LTDA - Emic (São José dos Pinhais, Brazil). This machine is similar to the Instron test machine used in a study that applied a similar method. ${ }^{3}$

A chisel-shaped rod was placed on the segment of orthodontic wire to be tested and a force of 50 newtons $(\mathrm{N})$ was applied by the machine.

The force was continuously applied at a crosshead speed of $1 \mathrm{~mm} / \mathrm{min}$ until deflections of 1 to 3 $\mathrm{mm}$ were obtained. Forces were recorded at each $0.5 \mathrm{~mm}$ deflection interval $(1 \mathrm{~mm} ; 1.5 \mathrm{~mm} ; 2 \mathrm{~mm}$; $2.5 \mathrm{~mm}$ and $3 \mathrm{~mm}$ ) at one hundredth $\mathrm{N}$ accuracy interval for each specimen (Figs 1, 2 and 3).

The Tesc 2.0 software was used to control all the trials: applying forces, reading results instantly and providing results in tables and graphs of load-deflection ratios. 


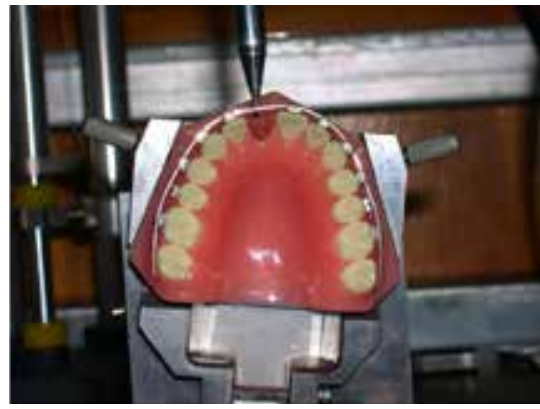

Figure 1-1 mm deflection.

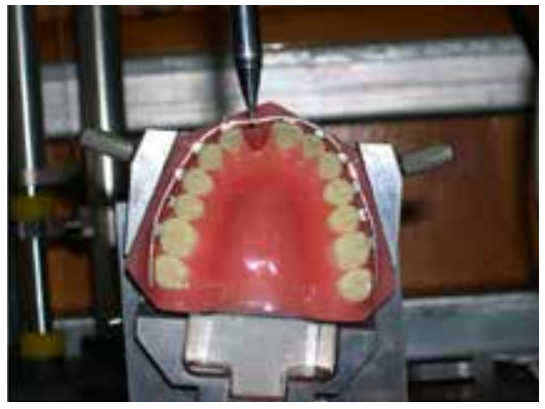

Figure 2- $2 \mathrm{~mm}$ deflection.

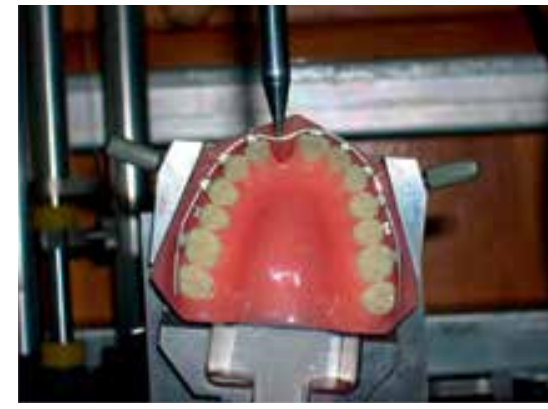

Figure 3-3 mm deflection.
Results were analyzed statistically to define the load-deflection ratio of the several orthodontic archwires of the four manufacturers tested and two types of metal alloys.

To compare differences in forces, the Student $t$ test was used because the measurements were expected to follow normal distributions. Means and standard deviations were calculated for the variables under study, and the Student $t$ test was used again to analyze results and evaluate whether the differences were statistically significant.

\section{RESULTS}

Figure 4 shows the load-deflection ratios of conventional NiTi wires and expresses mean values in $\mathrm{N}$ and deflections in $\mathrm{mm}$. Standard deviations of the loads applied were represented by vertical bars for each variable measured.

Figure 4 shows that the 3M Unitek wires had the lowest load-deflection ratio. The Ormco, Abzil and Morelli wires underwent less deflection when the highest loads were applied.

Figure 5 shows the load-deflection ratios of heatactivated NiTi wires and expresses mean load values in $\mathrm{N}$ and deflection in $\mathrm{mm}$. Standard deviations were represented by vertical bars for each variable measured.

In Figure 5, heat-activated NiTi wires with the lowest load-deflection ratio were the Ormco wires, which had substantially lower values than those found for the other wires under study. Mean values had a limit of $2.5 \mathrm{~mm}$ deflection, which resulted in a practically horizontal curve with a plateau of constant loads, which is typical of superelastic alloys.

The statistical differences in mechanical performance during activation of each alloy $(\mathrm{P}<0.05 \%=95 \%$;
$\mathrm{P}<0.01 \%=99 \% ; \mathrm{P}<0.001 \%=99.9 \%)$ were significant, as described below. The Morelli and Abzil wires had statistical differences of $5 \%$ at $1 \mathrm{~mm}$ and $2 \mathrm{~mm}$ deflections, but there was no significant difference at $2.5 \mathrm{~mm}$ and $3 \mathrm{~mm}$. The Morelli and 3M Unitek wires had 0.1\% statistically significant differences at $1 \mathrm{~mm}$ to $2 \mathrm{~mm}$ deflections; at $2.5 \mathrm{~mm}$ deflection, they had a $1 \%$ statistically significant difference, but there was no statistical difference at $3 \mathrm{~mm}$. The comparison of Abzil and $3 \mathrm{M}$ Unitek wires revealed significant differences of 5 to $0.1 \%$ up to deflections of $2.5 \mathrm{~mm}$, but no statistically significant values at $3 \mathrm{~mm}$.

For heat-activated NiTi wires of the same thickness, cross-sectional shape and chemical composition, there was a difference of about $32 \%$ when the Ormco and Morelli specimens were compared at $2 \mathrm{~mm}$ deflection.

Figure 6 shows the load-deflection ratios of conventional and heat-activated NiTi wires and expresses mean load values in $\mathrm{N}$ and deflections in $\mathrm{mm}$. Standard deviations were represented by vertical bars for each variable measured.

In Figure 6, the conventional NiTi wires had load-deflection ratios considerably greater than those found for heat-activated NiTi wires at all intervals under assessment.

Moreover, the curves for each wire under study could be used to classify them according to their load-deflection ratios, from more flexible to more rigid in the following order: heat-activated Ormco, heat-activated 3M Unitek, heat-activated Abzil, heat-activated Morelli, conventional 3M Unitek, conventional Ormco and conventional Abzil and Morelli wires.

Table 1 shows the load-deflection ratios of conventional NiTi wires of the different brands and 


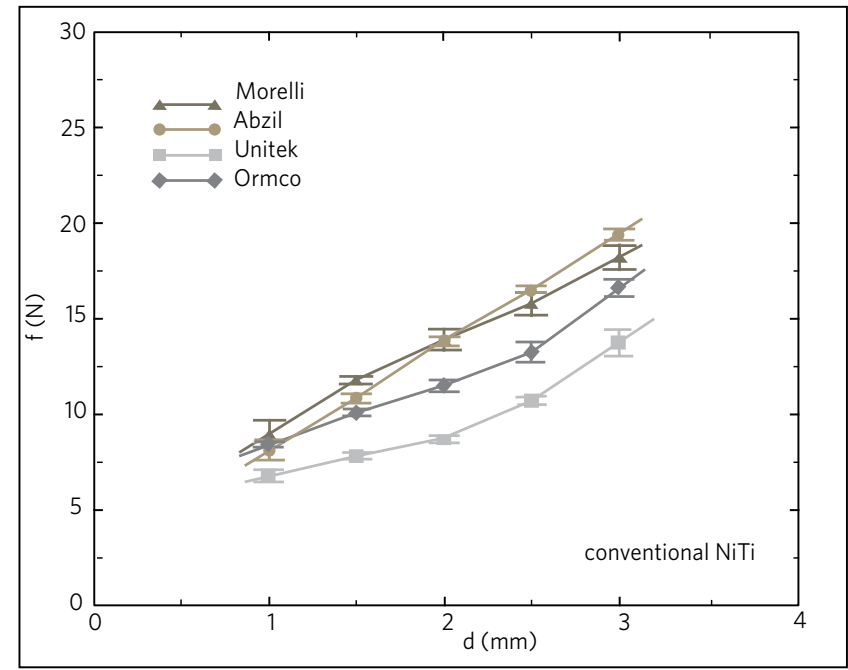

Figure 4 - Mean values for Load/Deflection rate of conventional $\mathrm{Ni}-\mathrm{Ti}$ wires.

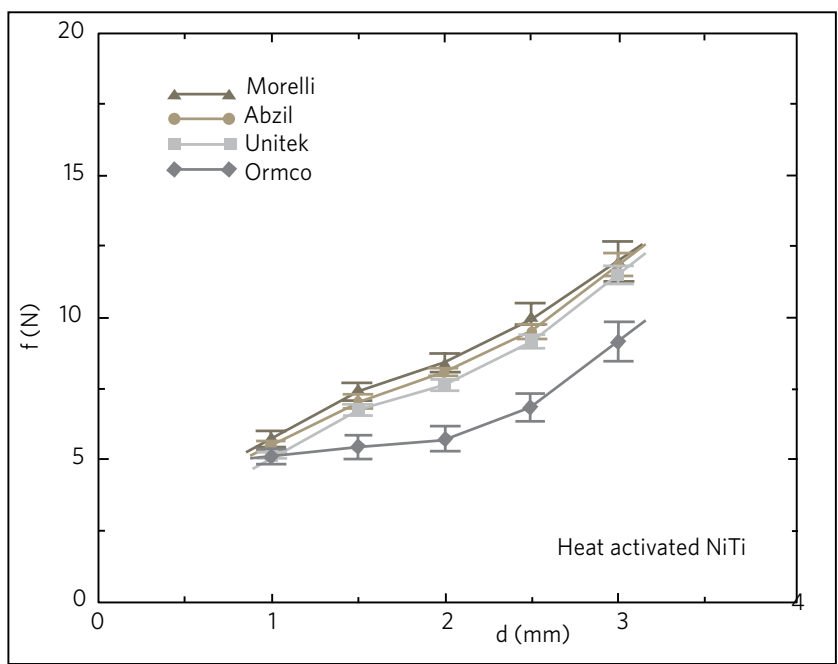

Figure 5 - Mean values for Load/Deflection rate of heat-activated $\mathrm{Ni}$-Ti wires.

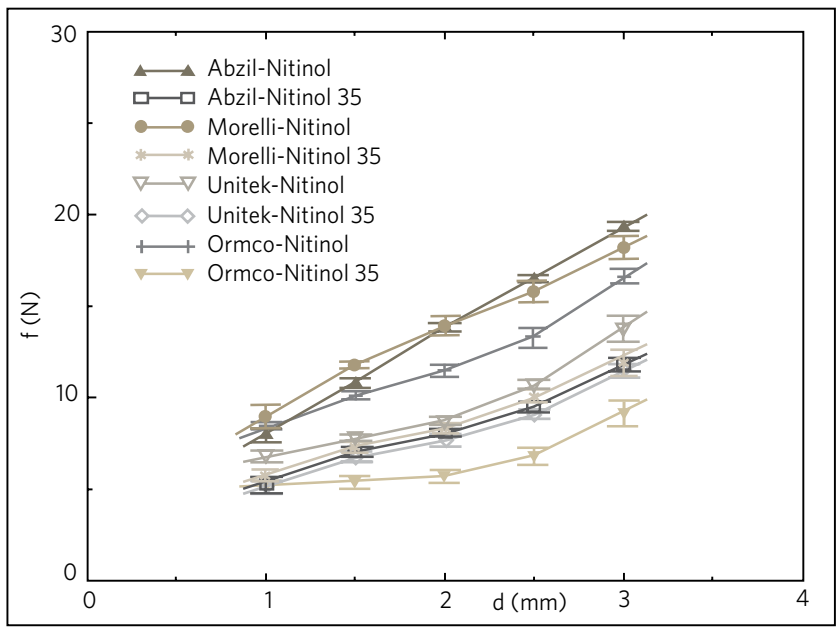

Figure 6 - Mean values for Load/Deflection rate of conventional and heat-activated $\mathrm{NiTi}$ wires and standard deviation (SD) represented by vertical lines. expresses mean values in $\mathrm{N}$ and deflections in $\mathrm{mm}$. Table 2 shows the load-deflection ratio of heat-activated NiTi wires and expresses mean load values in $\mathrm{N}$ and deflections in $\mathrm{mm}$.

\section{DISCUSSION}

In contemporary Orthodontics, treatments tend to be initiated with rectangular wires of alloys with the lowest modulus of elasticity and, during the treatment, wires are changed to use a different type of alloy, but not a different cross-sectional shape. Therefore, root torques may be controlled from the beginning, and treatment may be more stable, require a smaller number of office visits and result in fewer injuries to perioral tissues. In agreement with this point of view, we decided to analyze the behavior of wires that have the lowest moduli of elasticity: conventional $\mathrm{NiTi}$ and heat-activated $\mathrm{NiTi}$ wires in the cross-sectional dimensions (0.019 x 0.025-in) available in the Brazilian market. This choice was also justified by the fact that wire thickness affects elasticity. Therefore, this study raised the possibility of beginning treatment with rectangular wires of greater caliber changing only the modulus of elasticity at a more advanced phase of treatment. ${ }^{1}$

A comparison of the load-deflection ratios during the activation of several brands of 0.012-in, 0.014-in and 0.016-in round orthodontic wires of three different alloys, conducted by Rock and Wilson, ${ }^{3}$ revealed that conventional NiTi wires exerted light and constant forces. However, when the caliber of the wire changed from 0.014-in to 0.016-in, they found excessive activation forces that exceeded the $4 \mathrm{~N}$ limit even at low deflections, such as $1.5 \mathrm{~mm}$. In this study, however, the values for the $0.019 \times 0.025$-in rectangular wires exceeded this limit of load-deflection ratio even at low deflections (lower than $1 \mathrm{~mm}$ ), which indicates that this wire cannot be used in the aligning and leveling phase of orthodontic treatments.

In a study that used a method similar to ours, Nakano et $\mathrm{al}^{2}$ evaluated nine commercial brands of $0.016 \times 0.022$-in rectangular conventional and heatactivated NiTi wires. The authors found that the heat-activated Ormco wires had the lowest mean load-deflection ratio. The heat-activated Abzil wires were second in the scale from lowest to highest load-deflection ratios, followed by the conven- 
Table 1 - Values for Student T-Test and levels of significance for the comparison of load-deflection rate of conventional NiTi wires of different manufacturers.

\begin{tabular}{|c|c|c|c|c|c|c|c|}
\hline \multicolumn{3}{|c|}{ Conventional NiTi } & \multicolumn{5}{|c|}{ Deflection (mm) } \\
\hline (Manufacturers) & & & 1.0 & 1.5 & 2.0 & 2.5 & 3.0 \\
\hline \multirow{6}{*}{ Morelli } & \multirow{2}{*}{ Abzil } & $L$ & 3.58 & 9.64 & 0.49 & -3.36 & -5.32 \\
\hline & & $\mathrm{S}$ & 0.01 & 0.001 & NS & 0.01 & 0.001 \\
\hline & \multirow{2}{*}{ Unitek } & $L$ & 9.59 & 49.86 & 30.48 & 24.21 & 14.81 \\
\hline & & $\mathrm{S}$ & 0.001 & 0.001 & 0.001 & 0.001 & 0.001 \\
\hline & \multirow{2}{*}{ Ormco } & $L$ & 2.46 & 19.62 & 12.49 & 9.71 & 6.22 \\
\hline & & $S$ & 0.05 & 0.001 & 0.001 & 0.001 & 0.001 \\
\hline \multirow{4}{*}{ Abzil } & \multirow{2}{*}{ Unitek } & $L$ & 7.17 & 31.42 & 55.72 & 67.81 & 24.41 \\
\hline & & $\mathrm{S}$ & 0.001 & 0.001 & 0.001 & 0.001 & 0.001 \\
\hline & \multirow{2}{*}{ Ormco } & $L$ & -2.46 & 7.13 & 18.06 & 18.31 & 17.11 \\
\hline & & $\mathrm{S}$ & 0.05 & 0.001 & 0.001 & 0.001 & 0.001 \\
\hline \multirow{2}{*}{ Unitek } & \multirow{2}{*}{ Ormco } & $L$ & -15.79 & -28.97 & -25.81 & -14.40 & -11.18 \\
\hline & & $\mathrm{S}$ & 0.001 & 0.001 & 0.001 & 0.001 & 0.001 \\
\hline
\end{tabular}

L=Load (N); S=Significance; NS=Non-significant.

Table 2 - Values for the Student T-test and levels of significance for the comparison of the load-deflection rate for heat-activated NiTi wires of different manufacturers.

\begin{tabular}{|c|c|c|c|c|c|c|c|}
\hline \multicolumn{3}{|c|}{ Heat-activated NiTi } & \multicolumn{5}{|c|}{ Deflection (mm) } \\
\hline (Manufacturers) & & & 1.0 & 1.5 & 2.0 & 2.5 & 3.0 \\
\hline \multirow{6}{*}{ Morelli } & \multirow{2}{*}{ Abzil } & $L$ & 2.37 & 3.14 & 3.05 & 2.13 & 0.44 \\
\hline & & $\mathrm{S}$ & 0.05 & 0.05 & 0.05 & NS & NS \\
\hline & \multirow{2}{*}{ Unitek } & $L$ & 6.26 & 5.87 & 6.42 & 4.41 & 1.96 \\
\hline & & $\mathrm{S}$ & 0.001 & 0.001 & 0.001 & 0.01 & NS \\
\hline & \multirow{2}{*}{ Ormco } & $L$ & 4.51 & 12.53 & 15.65 & 13.45 & 9.09 \\
\hline & & $\mathrm{S}$ & 0.01 & 0.001 & 0.001 & 0.001 & 0.001 \\
\hline \multirow{4}{*}{ Abzil } & \multirow{2}{*}{ Unitek } & $L$ & 4.87 & 2.75 & 6.51 & 3.50 & 2.24 \\
\hline & & S & 0.01 & 0.05 & 0.001 & 0.01 & NS \\
\hline & \multirow{2}{*}{ Ormco } & $\mathrm{L}$ & 2.91 & 10.62 & 16.97 & 15.11 & 10.65 \\
\hline & & $\mathrm{S}$ & 0.05 & 0.001 & 0.001 & 0.001 & 0.001 \\
\hline \multirow{2}{*}{ Unitek } & \multirow{2}{*}{ Ormco } & $L$ & -0.07 & 9.20 & 13.14 & 13.80 & 9.86 \\
\hline & & S & NS & 0.001 & 0.001 & 0.001 & 0.001 \\
\hline
\end{tabular}

L=Load (N); S=Significance; NS=Non-significant.

tional wires of the same brand. The wires with the highest load-deflection ratio were the conventional and heat-activated 3M Unitek. However, in this study, the Abzil wires almost always had the highest values of load-deflection ratio when compared with wires of the same or different alloys. Nakano et $\mathrm{al}^{2}$ also compared the performance of conventional and heat-activated NiTi wires to each other, both with a thickness of 0.016-in, and found that the level of forces exerted at $3 \mathrm{~mm}$ deflection was $17 \mathrm{~g}$ to $153 \mathrm{~g}$ and $17 \mathrm{~g}$ to $100 \mathrm{~g}$. The results showed that heat-activated wires exerted better force distribution than conventional NiTi, which corroborates to the findings presented in our study.

Using materials and methods similar to the ones of our study, Gurgel et $\mathrm{al}^{5}$ studied the performance of 
$0.017 \times 0.025$-in rectangular conventional and heatactivated wires of several commercial brands. Among the brands, there were Morelli, Ormco and 3M Unitek samples. They found that the Ormco heat-activated NiTi wire had the lowest load-deflection ratio during activation, as in our study.

A considerable difference between another study conducted by Gurgel et $\mathrm{al}^{5}$ and the results of our study was found for the conventional Morelli NiTi wires, which had the highest loads during activations along all our study. However, in their other study, Gurgel et $\mathrm{al}^{5}$ found one of the lowest load-deflection ratios between six brands under study, and the flexibility of the Morelli wire was second only to the Ormco heat-activated wires.

\section{CONCLUSIONS}

Our results suggest that:

1. The comparisons of mean load-deflection values of conventional NiTi wires of different commercial brands revealed that the lowest meandeflection ratio was found for the $3 \mathrm{M}$ Unitek wire, followed by Ormco, Morelli and Abzil.
2. The comparisons of mean load-deflection values of heat-activated NiTi wires of different commercial brands revealed that the lowest mean-deflection ratio was found for the Ormco wire, followed by $3 \mathrm{M}$ Unitek, Abzil and Morelli.

3. The comparison of mean load-deflection ratios for the conventional and heat-activated wires revealed that heat-activated wires had lower mean loaddeflection ratios than conventional NiTi wires, and this trend was seen along all the study. However, at 2-mm deflection, heat-activated Morelli wires and conventional 3M Unitek wires had very close mean load-deflection ratios, and their difference was not statistically significant, indicating that their performances were similar at this deflection.

\footnotetext{
REFERENCES

1. Burstone CJ Variable-modulus orthodontics. Am J Orthod. 1981;80(1):1-16

2. Nakano H, Satoh K, Norris R, Jin T, Kamegai T, Ishikawa F, Katsura $\mathrm{H}$. Mechanical properties of several nickel-titanium alloy wires in three-point bending tests. Am J Orthod Dentofacial Orthop. 1999 Apr;115(4):390-5.

3. Rock WP, Orth D, Wilson HJ, Tech M, Chem C. Forces exerted by orthodontic aligning archwires. Br J Orthod. 1988;15(4):55-9.

4. Schwarz AM. Tissue changes incidental to orthodontic tooth movement. Int J Orthod. 1932;5(18):331-52.

5. Gurgel JA, Ramos AL, Kerr SD. Fios ortodônticos. Rev Dental Press Ortodon Ortop Facial. 2001 jul-ago;6(4):103-14.

6. Waters NE, Houston WJB, Stephens CD. An experimental investigation into the effect of dimensional change on the stiffness of double vertical incisor alignment loops. Eur J Orthod. 1988 Nov;10(4):319-28
} 